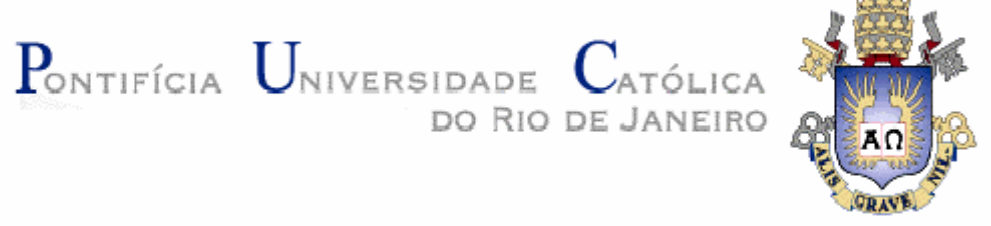

Fátima Cristina de M. Alves

\title{
QUALIDADE NA EDUCAÇÃO FUNDAMENTAL PÚBLICA NAS CAPITAIS BRASILEIRAS: TENDÊNCIAS, CONTEXTOS E DESAFIOS
}

\begin{abstract}
Tese de Doutorado
Tese apresentada ao Programa de Pósgraduação em Educação da PUC-Rio como requisito parcial para a obtenção do título de Doutor em Educação.
\end{abstract}

Orientador: Creso Franco

Rio de Janeiro, março de 2007 


\title{
PontifícIa $U_{\text {Miversidade }} C_{\text {atólloa }}$

Fátima Cristina de M. Alves

\section{QUALIDADE NA EDUCAÇÃO FUNDAMENTAL PÚBLICA NAS CAPITAIS BRASILEIRAS: TENDÊNCIAS, CONTEXTOS E DESAFIOS}

Tese apresentada como requisito parcial para a obtenção do grau de Doutor pelo Programa de Pós-graduação em Educação do Departamento de Educação do Centro de Teologia e Ciências Humanas da PUC-Rio. Aprovada pela Comissão Examinadora abaixo assinada.

\author{
Prof. Creso Franco \\ Orientador \\ PUC-Rio \\ Prof ${ }^{a}$ Sonia Kramer \\ Presidente \\ PUC-Rio \\ Prof ${ }^{a}$ Isabel Alice Oswald Monteiro Lelis \\ PUC-Rio
}

Prof. Luiz César de Queiroz Ribeiro UFRJ

Prof. Reynaldo Fernandes

USP

Prof. PAULO FERNADO CARNEIRO DE ANDRADE Coordenador Setorial do Centro de Teologia e Ciências Humanas PUC-Rio

Rio de Janeiro, 23 de março de 2007 
Todos os direitos reservados. É proibida a reprodução total ou parcial do trabalho sem autorização do autor, do orientador e da universidade.

Fátima Cristina de M. Alves

Licenciada em Ciências Biológicas pela UFRJ em 1996. Mestre em Educação pela UFF em 2001. De 2000 a 2003 foi pesquisadora da Coordenação de Educação em Ciências do Museu de Astronomia e Ciências Afins na área de educação não formal e desenvolvendo atividades relacionadas à divulgação científica. Desde 2004 é pesquisadora assistente do Laboratório de Avaliação da Educação realizando pesquisas sobre temas relacionados à política educacional, avaliação, eficácia, eqüidade e desigualdades educacionais.

Ficha Catalográfica

Alves, Fátima Cristina de M.

Qualidade na educação fundamental pública nas capitais brasileiras : tendências, contextos e desafios / Fátima Cristina de M. Alves ; orientador: Creso Franco. - 2007.

243 f. : il. (col.) ; $30 \mathrm{~cm}$

Tese (Doutorado em Educação)-Pontifícia Universidade Católica do Rio de Janeiro, Rio de Janeiro, 2007.

Inclui bibliografia

1. Educação - Teses. 2. Qualidade da educação. 3. Políticas educacionais. 4. Modelagem multinível. 5. Capitais brasileiras. I. Franco, Creso. II. Pontifícia Universidade Católica do Rio de Janeiro. Departamento de Educação. III. Título.

CDD: 370 


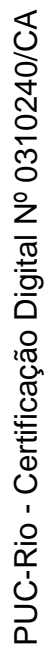

Para Augusto e Elizabeth. 


\section{Agradecimentos}

Momentos de agradecimentos sempre são carregados de emoção. Este não poderia ser diferente. Durante o doutorado tive encontros com várias pessoas que, direta ou indiretamente, deixaram marcas na minha formação. Desde já agradeço a todas. Não poderia deixar de registrar meus agradecimentos especiais a pessoas sem as quais eu não realizaria este trabalho.

Ao meu orientador, Creso Franco, por estar sempre presente na minha trajetória acadêmica apoiando e incentivando o meu crescimento profissional e pessoal. Pelas inúmeras oportunidades que tive de aprender e por confiar na minha capacidade - mesmo quando eu duvidava...

À Alicia Bonamino que, além de professora competente e dedicada, tornou-se uma amiga adorada. Pelas inúmeras conversas, desabafos, risadas...

À Sibele Cazelli, Esther Valente e Diana Mandelert com as quais minhas fraquezas tornam-se menores, as durezas mais suaves e a vida mais divertida...

Aos companheiros do LAED, especialmente Elisangela, Natália, Glauco e Fernanda, pela amizade e solidariedade que marcaram nosso convívio...

Aos professores que participaram da comissão julgadora pela condução do debate acadêmico...

Aos professores do Departamento de Educação da PUC-Rio, em especial à Zaia Brandão e Apparecida Mamede, pelas contribuições na minha formação...

Aos amigos do CAED, Tufi, Lina Kátia, Ailton e Wellington, pela ajuda, discussões enriquecedoras e enorme hospitalidade...

Aos diversos companheiros de doutorado, em especial à "Casa das Sete Mulheres", pelas trocas de experiências, artigos e aflições...

Ao Instituto Nacional de Estudos e Pesquisas Educacionais Anísio Teixeira pela concessão das bases de dados do Censo Escolar e do SAEB ... 
Ao Professor Ruben Klein por sua disponibilidade em me ensinar as peculiaridades do Censo Escolar...

À Vanessa Néspoli por sua presteza e atenção no atendimento as minhas solicitações com relação às bases do Censo Escolar...

Ao pessoal da Secretaria do Departamento de Educação, Geneci, Patrícia, Janaína, Sandra e Marcelo, pelas inúmeras vezes que me ajudaram...

À FAPERJ - Programa de Bolsa Nota 10 - à PUC-Rio e à Fundação Ford pelo fomento a minha pesquisa...

A minha família, Günther, minha mãe, meus irmãos e meus cunhados, pelo incentivo, apoio, orgulho e, sobretudo, muito amor...

Ao pessoal aracajuano pela torcida e o carinho, em especial ao Zezé, por ceder seu espaço e pelo café reconfortante...

...muito obrigada!! 


\section{Resumo}

Alves, Fátima; Franco, Creso. Qualidade na Educação Fundamental Pública nas Capitais Brasileiras: Tendências, Contextos e Desafios. Rio de Janeiro, 2007. 243p. Tese de Doutorado - Departamento de Educação, Pontifícia Universidade Católica do Rio de Janeiro.

Este trabalho investiga a qualidade do Ensino Fundamental das capitais brasileiras no período de 1996 a 2005 face às mudanças expressivas que ocorreram na educação no Brasil, principalmente no que se refere à alteração no fluxo escolar, ao papel dos municípios na administração e ao modo heterogêneo pelo qual cada um destes fatores atuou nas diferentes redes de ensino das capitais. Inicialmente, o estudo analisa a evolução de três indicadores de qualidade do Ensino Fundamental - desempenho escolar, taxa de não aprovação e taxa de distorção idade série - das redes de ensino estaduais e municipais das capitais brasileiras, bem como o mapeamento das políticas educacionais implementadas pelos governos no período analisado. Em seguida, investigou-se a associação das políticas públicas sobre o desempenho das redes de ensino das capitais brasileiras, a partir dos dados para a $4^{\text {a }}$ série do Ensino Fundamental do SAEB 1999, 2001 e 2003. O resultado da estimação do modelo multinível mostrou que as políticas relacionadas ao processo de escolha dos diretores, à formação dos professores, ao atendimento à Educação Infantil têm associação positiva no desempenho discente. $\mathrm{O}$ trabalho também investiga, a partir do desempenho da coorte etária de 10 anos, a qualidade da educação considerando tanto o desempenho dos alunos quanto o fluxo escolar. Os resultados indicam, para o Brasil, queda de 7,5 pontos entre 1995 e 2003. Para as capitais brasileiras, o cenário para o período 1999 a 2003 é de estabilidade. Consequiências para as políticas públicas na área de educação são discutidas.

\section{Palavras chave}

Qualidade da educação, Políticas Educacionais, Modelagem multinível, Capitais Brasileiras. 


\section{Abstract}

Alves, Fátima; Franco, Creso. Quality in the Public Basic Education in the capital of the Brazilian states: Trends, Contexts and Challenges. Rio de Janeiro, 2007. 243p. Tese de Doutorado - Departamento de Educação, Pontifícia Universidade Católica do Rio de Janeiro.

The present study investigates the overall quality of basic schools located in the capital of the Brazilian states, between 1996 and 2005, taking into account the extensive changes throughout Brazilian education system, specially major improvement in the Brazilian educational flux, the roll of municipal administration on education, as well as the different ways in which each of the aforementioned factors influenced municipal and state schools. At first, our study not only analyses the evolution of three basic schools quality indexes - school performance, retention rates, and overage rates - of both municipal and state schools located in capital of the Brazilian states, but also the mapping of government implemented education policies in the mentioned period. Subsequently, we study the relationship between the public policies on schools performance, using the available information of Brazilian Assessment of Educational Progress (SAEB), $4^{\text {th }}$ grade, in data base for 1999,2001 , and 2003. The multi-level estimation results showed that policies related to schools principals choosing process, teachers' education and childhood education are associated to an increased schools performance. Another object of analysis is the quality of education for the cohort of 10 year-olds. The results indicate stability for 10 year-olds advancement performance to the capital of the Brazilian states. Consequences for educational policy are discussed.

\section{Keywords}

Quality of education, Educational Policy, HLM, Brazilian States capitals 


\section{SUMÁRIO}

1. Introdução

16

2. A Evolução dos Indicadores de Qualidade da Educação Fundamental nas Capitais Brasileiras.......................................... 23

2.1 Educação, acesso e matrículas ...................................... 23

2.2 Rendimento Escolar: Taxa de Não-Aprovação ............... 34

2.3 Rendimento Escolar: Taxa de Defasagem Idade Série .... 41

2.4 Desempenho Educacional ........................................... 46

3. Mapeamento das Políticas Educacionais das Redes de Ensino das Capitais Brasileiras

3.1 Eixo: Organização Escolar

Política/ Programa: Escolarização em Ciclos

3.2 Eixo: Organização Escolar

Política/ Programa: Ensino Fundamental de nove

anos

3.3 Eixo: Atendimento à Educação Infantil

Política/ Programa: Taxa de atendimento à Educação

Infantil

3.4 Eixo: Correção de Fluxo

Política/ Programa: Programas de correção da

defasagem idade série

3.5 Eixo: Transparência e Responsabilização

Política/ Programa: Sistema de Avaliação de

Desempenho dos Alunos

3.6 Eixo: Autonomia das Unidades Escolares

Política/ Programa: Programa Federal Dinheiro Direto

na Escola

3,7 Eixo: Autonomia das Unidades Escolares

Política/ Programa: Escolha do Diretor Escolar

104

3.8 Eixo: Formação Docente

Política/ Programa: Nível de formação inicial

dos professores

4. Políticas Educacionais nas Redes Públicas e Desempenho Escolar dos Alunos das Capitais Brasileiras 
5. Desempenho, Fluxo Escolar e Políticas Educacionais

130

5.1 Desempenho da geração de 10 anos no Brasil e nas capitais brasileiras: metodologia

5.2 Desempenho da geração de 10 anos no Brasil e nas capitais brasileiras: resultados

5.3 Desempenho da geração de 10 anos nas capitais brasileiras e Políticas Educacionais

6. Conclusões

7. Bibliografia 159

8. Anexos 167 


\section{Lista de Tabelas e Quadros}

\section{Tabelas}

Tabela 1: Indicadores educacionais - número médio de anos de escolaridade na população de 25 anos ou mais e percentual de crianças de 7 a 14 anos na escola nos anos de 1991 e 2000 nas Capitais Brasileiras

Tabela 2: Distribuição das redes de ensino das capitais brasileiras de acordo com as taxas de não aprovação do Ensino Fundamental em 2004.

Tabela 3: Distribuição das redes de ensino das capitais brasileiras de acordo com a taxa de distorção idade série.

Tabela 4: Distribuição das redes de ensino das capitais brasileiras de acordo com as médias de desempenho em matemática da $4^{\mathrm{a}}$ série do Ensino Fundamental.....

Tabela 5: Distribuição das redes de ensino das capitais brasileiras de acordo com as médias de desempenho em matemática da $4^{\mathrm{a}}$ série do Ensino Fundamental, ajustadas por NSE.

Tabela 6: Modelo Multinível do desempenho de matemática da $4^{a}$ série do Ensino Fundamental para as redes de ensino públicas das capitais brasileiras .......

Tabela 7: Distribuição das redes de ensino das capitais brasileiras de acordo com as médias de desempenho em matemática da $4^{\mathrm{a}}$ série do Ensino Fundamental, ajustadas por condições da rede de ensino.

Tabela 8: Estatística descritiva das variáveis utilizadas

Tabela 9: Modelo Multinível do desempenho de matemática da $4^{a}$ série do Ensino Fundamental para as redes de ensino públicas das capitais brasileiras

Tabela 10: Aprendizagem entre diferentes séries do Ensino Fundamental, a partir da diferença entre o desempenho médio de determinados grupos de idade a partir de dados do Nova Escola 2004.

Tabela 11: Modelo Multinível do desempenho de matemática da geração de crianças de 10 anos e da $4^{\mathrm{a}}$ série do Ensino Fundamental para as redes de ensino públicas das capitais brasileiras

\section{Quadros}

Quadro 1: Atributos dos eixos de análise utilizados no mapeamento.

Quadro 2: Variáveis Utilizadas na Modelagem do Nível 2

Quadro 3: Descrição dos procedimentos utilizados para calcular o desempenho da geração 


\section{Lista de Gráficos}

Gráfico 1: Distribuição da matrícula, por rede, para a $1^{\mathrm{a}}$ a $4^{\mathrm{a}}$ séries do Ensino Fundamental nas Capitais Brasileiras.

Gráfico 2: Distribuição da matrícula, por rede, para a $5^{\mathrm{a}}$ a $8^{\mathrm{a}}$ séries do Ensino Fundamental nas Capitais Brasileiras

Gráfico 3: Distribuição da matrícula, por rede, de $1^{\mathrm{a}}$ a $4^{\mathrm{a}}$ séries do Ensino Fundamental nas capitais brasileiras em 1996.

Gráfico 4: Distribuição da matrícula, por rede, de $1^{\mathrm{a}} \mathrm{a} 4^{\mathrm{a}}$ séries do Ensino Fundamental nas capitais brasileiras em 2005.

Gráfico 5: Distribuição da matrícula, por rede, de $5^{\mathrm{a}}$ a $8^{\mathrm{a}}$ séries do Ensino Fundamental nas capitais brasileiras em 1996.

Gráfico 6: Distribuição da matrícula, por rede, de $5^{\mathrm{a}}$ a $8^{\mathrm{a}}$ séries do Ensino Fundamental nas capitais brasileiras em 2005.

Gráfico 7: Evolução da taxa de não aprovação do Ensino Fundamental no Brasil.

Gráfico 8: Evolução da taxa de não aprovação do Ensino Fundamental para o Brasil e para as capitais no período de 1996 a 2004.

Gráfico 9: Evolução da taxa de não aprovação do Ensino Fundamental para o Brasil e para as capitais por dependência administrativa.

Gráfico 10: Evolução da taxa de não aprovação do Ensino Fundamental para João Pessoa por dependência administrativa.

Gráfico 11: Evolução da taxa de não aprovação do Ensino Fundamental para Aracaju por dependência administrativa

Gráfico 12: Evolução da taxa de não aprovação do Ensino Fundamental para Recife por dependência administrativa.

Gráfico 13: Evolução da taxa distorção idade série do Ensino Fundamental para o Brasil e para as capitais

Gráfico 14: Evolução da taxa de distorção idade série do Ensino Fundamental para o Brasil e para as capitais por dependência administrativa.

Gráfico 15: Evolução da taxa distorção idade série do Ensino Fundamental da rede estadual de Belém nos anos de 1996 a 2003.

Gráfico 16: Evolução da taxa distorção idade série do Ensino Fundamental da rede estadual de São Paulo nos anos de 1996 a 2003. 


\section{Lista de Gráficos}

Gráfico 17: Evolução das médias em matemática da $4^{\mathrm{a}}$ série do Ensino

Fundamental para o Brasil e para as Capitais.

Gráfico 18: Evolução das médias em matemática da $4^{\mathrm{a}}$ série do Ensino

Fundamental para o Brasil e para as Capitais por dependência administrativa

Gráfico 19: Evolução das médias em matemática da $4^{\mathrm{a}}$ série do Ensino

Fundamental para as capitais da Região Norte.

Gráfico 20: Evolução das médias em matemática da $4^{\mathrm{a}}$ série do Ensino

Fundamental para as capitais da Região Nordeste.

Gráfico 21: Evolução das médias em matemática da $4^{\mathrm{a}}$ série do Ensino

Fundamental para as capitais da Região Sudeste

Gráfico 22: Evolução das médias em matemática da $4^{\mathrm{a}}$ série do Ensino

Fundamental para as capitais da Região Sul.

Gráfico 23: Evolução das médias em matemática da $4^{\mathrm{a}}$ série do Ensino

Fundamental para as capitais da Região Centro-Oeste.

Gráfico 24: Evolução das médias em matemática da $4^{\mathrm{a}}$ série do Ensino

Fundamental para Maceió por dependência administrativa.

Gráfico 25: Evolução das médias em matemática da $4^{\mathrm{a}}$ série do Ensino

Fundamental para Belo Horizonte por dependência administrativa

Gráfico 26: Evolução das médias em matemática da $4^{\mathrm{a}}$ série do Ensino

Fundamental para Recife por dependência administrativa

Gráfico 27: Evolução das médias em matemática da $4^{\mathrm{a}}$ série do Ensino

Fundamental para Porto Velho por dependência administrativa

Gráfico 28: Evolução das médias em matemática da $4^{\mathrm{a}}$ série do Ensino

Fundamental para Teresina por dependência administrativa.

Gráfico 29: Evolução das médias em matemática da $4^{\mathrm{a}}$ série do Ensino

Fundamental de redes de ensino com melhora constante.

Gráfico 30: Evolução das médias em matemática da $4^{\mathrm{a}}$ série do Ensino

Fundamental de redes de ensino com piora constante.

Gráfico 31: Evolução das médias e das médias ajustadas por NSE em matemática da $4^{\mathrm{a}}$ série do Ensino Fundamental para o Rio de Janeiro.

Gráfico 32: Evolução das médias e das médias ajustadas por NSE em matemática da $4^{\mathrm{a}}$ série do Ensino Fundamental para Aracaju. 


\section{Lista de Gráficos}

Gráfico 33: Evolução das médias e das médias ajustadas por condições escolares em matemática da $4^{\mathrm{a}}$ série do Ensino Fundamental para Rio de Janeiro.

Gráfico 34: Evolução do percentual de escolas das redes estaduais e municipais para o conjunto das capitais brasileiras que receberam recursos do PDDE de 1999 a 2004.

Gráfico 35: Evolução do percentual de turmas da $4^{\mathrm{a}}$ série do Ensino Fundamental com professores com ensino superior nos anos de 1999, 2001 e 2003.

Gráfico 36: Efeito do processo de escolha de diretor envolvendo seleção e eleição sobre o desempenho médio das redes de ensino das capitais brasileiras......

Gráfico 37: Efeito do aumento de 25 e de 50 pontos percentuais em relação à taxa média de atendimento à Educação Infantil sobre o desempenho médio das redes de ensino das capitais brasileiras.

Gráfico 38: Efeito do aumento de 25 e de 50 pontos percentuais em relação à taxa média de atendimento à Educação Infantil sobre o desempenho médio das redes de ensino das capitais brasileiras.

Gráfico 39: Evolução da média de proficiência em matemática da $4^{\mathrm{a}}$ série do Ensino Fundamental no Brasil nas avaliações do SAEB de 1995 a 2003

Gráfico 40: Evolução do percentual de crianças da geração de 10 anos adiantadas, em fase e atrasadas tendo como referência a $4^{\mathrm{a}}$ série do Ensino Fundamental para o Brasil entre 1996 e 2004

Gráfico 41: Evolução do percentual de crianças da geração de 10 anos adiantadas, em fase e atrasadas tendo como referência a $4^{\mathrm{a}}$ série do Ensino Fundamental para as capitais brasileiras

Gráfico 42: Evolução do desempenho em matemática médio. Série X Geração. Brasil - 1995 a 2003. $4^{\text {a }}$ série como referência.

Gráfico 43: Evolução do desempenho em matemática do $1^{\mathrm{a}}$ quartil. Série $\mathrm{X}$ Geração. Brasil - 1995 a 2003. $4^{\mathrm{a}}$ série como referência.

Gráfico 44: Evolução do desempenho em matemática do $3^{\mathrm{a}}$ quartil. Série $\mathrm{X}$ Geração. Brasil - 1995 a 2003. $4^{\mathrm{a}}$ série como referência.

Gráfico 45: Evolução do desempenho em matemática médio. Série X Geração. Capitais - 1999 a 2003. $4^{\text {a }}$ série como referência.

Gráfico 46: Evolução do desempenho em matemática $1^{\circ}$ quartil. Série X Geração. Capitais - 1999 a 2003. $4^{\mathrm{a}}$ série como referência

Gráfico 47: Evolução do desempenho em matemática $3^{\circ}$ quartil. Série $X$ Geração. Capitais - 1999 a 2003. $4^{\text {a }}$ série como referência 


\section{Lista de Figuras}

Figura 1: Organização do Ensino Fundamental - Primeiro Segmento - nas redes estaduais e municipais das capitais brasileiras em 2005

Figura 2: Duração do Ensino Fundamental nas redes estaduais e municipais das capitais brasileiras em 2005 .

Figura 3: Taxa de atendimento à Educação Infantil em instituições registradas no cadastro do Censo Escolar em 1999 e em 2004.

Figura 4: Programas de Correção de Fluxo (IAS) das redes estaduais e municipais das capitais brasileiras em atividade nos anos de 2004 e 2005

Figura 5: Taxa de distorção idade série para o primeiro segmento do Ensino Fundamental das redes estaduais e municipais das capitais brasileiras em 2005.

Figura 6: Programas Avaliação de Desempenho de Alunos das redes estaduais e municipais das capitais brasileiras entre 2003 e 2005.

Figura 7: Percentual de escolas das redes estaduais e municipais para o conjunto das capitais brasileiras que receberam recursos do PDDE em 2005.

Figura 8: Moda da forma de escolha dos diretores nas redes Estaduais e Municipais das capitais brasileiras em 1999

Figura 9: Moda da forma de escolha dos diretores nas redes Estaduais e Municipais das capitais brasileiras em 2003.

Figura 10: Percentual de turmas de $4^{a}$ série do Ensino Fundamental com cujos professores têm ensino superior das redes estaduais e municipais das capitais brasileiras em 1999

Figura 11: Percentual de turmas de $4^{\mathrm{a}}$ série do Ensino Fundamental com cujos professores têm ensino superior das redes estaduais e municipais das capitais brasileiras em 2003. 